\title{
Selected outcomes of community- oriented, problem-based nursing programmes in South Africa.
}

\author{
NS Gwele, PhD, School of Nursing, University of Natal \\ PA Mclnerney, PhD, School of Nursing, University of Natal \\ $L$ van Rhyn, D Soc Sc, School of Nursing, University of the Free State \\ LR Uys, D Soc Sc, School of Nursing, University of Natal \\ T Tanga, PhD, School of Nursing Science, University of Transkei
}

\section{Abstract}

Whilst there is a significant body of research on the outcomes of problem-based learning (PBL) programmes (Albanese and Mitchell, 1993; Vernon and Blake, 1993), there is little information regarding the outcomes of community-oriented programmes (COL) for nursing students. Between 1994 and 1997, four university schools of nursing implemented problem-based, community-oriented learning (COL) programmes. This research sought to describe, evaluate and compare the outcomes of graduates from these four universities with graduates who had followed conventional programmes.

Research objectives. These were to describe and explore the incorporation of illness prevention and health promotion of graduates from PBL/COL programmes and non-PBL/COL programmes in South Africa, as described by the graduates and their supervisors. Secondly, to describe whether and how the graduates from PBL/COL and non-PBL/COL programmes engaged themselves in continued learning.
Research Methodology. This was a qualitative evaluation study, which is descriptive and comparative in nature. In-depth interviews were held with the graduates and their supervisors about six months after completion of their training. Use was made of Miller and Crabtree's (1994) Template Analysis Style and of Benner's (1984) interpretative approach to analyze data. Analysis was done using the NVIVO computer programme. This programme was used to manage the categories which were developed with regard to each concept as the analysis proceeded.

Findings.Both the graduates and the supervisors appeared to have difficulty describing activities relating to health promotion and illness prevention. Only three types of health promotion were described - mass education, increasing personal skills and creating a supportive environment. The most commonly mentioned means of illness prevention were health education and medical-surgical asepsis. A few graduates described activities which indicated that they had taken context into consideration during patient care.

\section{Introduction}

Although there has been a significant body of research over the last two decades on the outcomes of problembased learning (PBL) programmes (Albanese and Mitchell, 1993; Vernon and Blake, 1993), very little could be found in the literature in terms of the evaluation of community-oriented learning (COL) programmes. A COL programme aims to, amongst others, improve the functioning of graduates in the field of health promotion and illness prevention.

In a study to evaluate how well nurses are prepared in traditional programmes for their health education role, Latter, Rycroft-Malone, Yerrell \& Shaw (2000:1282) did a case study based project in three educational institutions in the
UK. They looked at three aspects of this function as applied to medication teaching; knowledge of content to be taught, patient education knowledge and communication skills. They found all three aspects to be problematic. Nurses did not know the pharmacology well enough to teach patients, they did not know the evidence about patient education on which to base their teaching, and they had insufficient practice opportunity to integrate this skill into their practice.

With regard to PBL programmes, one of the stated aims is to create life-long learners (Little \& Ryan, 1988 : 33). Again, no outcome evaluation studies that address this aspect could be found.

Outcomes evaluation about these concepts are necessary, 
since South African nurses in Primary Health Clinics are expected to provide a competent comprehensive primary level service after their basic nursing education. There has also been an increasing understanding that professionals should be self-directed learners, who are competent to continue their own learning after graduation. Whether this educational aim is realized has also rarely been evaluated.

Over the last few years, four nursing schools at different South African universities have implemented problembased (PBL) and Community-oriented (COL) pre-registration programmes. These are the University of Natal in 1994; the University of the Witwatersrand in 1995; the University of the Transkei (UNITRA) in 1997 and the University of the Free State in 1997.

In all four PBL/COL programmes, implemented at the four universities, all nursing courses are taught using PBL, whilst all the other courses are taught conventionally. In all of them students spend significant amounts of time in community settings.

\section{Literature survey}

\section{The concept of Community Oriented Learning (COL)}

Community based education can be seen as a means of achieving educational relevance to community needs and consequently of implementing a community-orientated educational program. It consists of learning activities that use the community extensively as a learning environment, in which not only students but also teachers, members of the community and representatives of other sectors are actively engaged throughout the educational experience. It needs to be conducted wherever people live i.e. in rural, suburban or urban areas (WHO, 1987:31). It is a process that aims to equip health personnel with the knowledge to be responsive to the health needs of the people and to enhance the ability of the health personnel to make an appropriate contribution to the improvement of the health care system.

The difference between a community-based and a community-oriented curriculum seems to lie only in the extent to which either community-based learning activities dominate the curriculum. If more than $50 \%$ of the total clinical learning experiences are community-based, the curriculum is classified as community based. If there is a significant focus on community-based experiences, but the 50\% level is not quite reached, it is a community-oriented curriculum.

Richards and Phlop (1987) give more detailed criteria that one can use to evaluate a curriculum in this regard:

- The extent to which the guiding principles of the school are community-oriented.

- The extent to which community-based learning forms part of the clinical exposure of students.

- The degree of community involvement in the training program.

- The degree to which the school has organizational linkages with health services other than with hospitals.

- The emphasis placed on knowledge and skills about community and population level assessment and intervention strategies.

A simple, but very useful, definition is that of Eshleman and Davidhizar (1997:24), which equates community-based education with health promotion and population-focused practice.

\section{The motivation for COL:}

To achieve the goals of HEALTH FOR ALL, health providers and planners must fully know and understand the needs of the population. They should have sound relationships with the people in their own context and thoroughly understand the way that people work and live. CBE promotes a meaningful assessment of the community's demographic, morbidity and mortality profiles and stimulates community participation and rational planning (Blecher and Frankish, 1995).

The interaction between the health of individuals and their environment is a subtle and complex interplay of physical, biological and social factors. It is therefore necessary to have experienced the context to appreciate and understand thoroughly how illness and the human experience of disease manifest themselves in different settings. It is also necessary to understand how to intervene in ways that are acceptable and efficient (University of Natal, 1991).

The goal of CBE is to teach students in the areas in which they are potentially likely to work. This inevitably requires that students be taught in a rich variety of contexts. South Africa with its diversity of ethnic groups and social classes presents a specific challenge. Teaching should take place in urban, peri urban, semi rural and rural areas. It should take place in situations ranging from elementary primary health care facilities to sophisticated tertiary hospital laboratories. It could e.g. include attachment to an inner city health project, where substance abuse, or street children are a problem, or experience in an immunization programme in a rural clinic with serious cold chain problems. Ideally academic institutions should develop a network of academic community health centers to complement the existing hospitals.

In the education of health professionals, experiential learning has always played an important role, and takes up a large proportion of learning time. In many ways it seems to be more important than classroom learning with regard to attitudes and perceptions of students. It is therefore extremely important that community based care, in which the Primary Health Care philosophy can be actively demonstrated, forms a large part of this type of learning for nurses. To achieve this goal, the following principles have to be incorporated into the programme:

- $\quad$ Community based student activities should relate to planned educational goals and both the students and the teachers must have a clear understanding of the purpose of the activities and the expected results (WHO, 1987:45).

- The activities should be introduced very early in the educational experience so that the student will internalise comprehensive management right from the beginning of her training and it must continue throughout the educational program. 
Community based activities must be viewed not as peripheral or casual experiences but as a standard integral and continuing part of the educational process.

- The students' work during training is thus 'real' work that is related to educational needs and also forms part of the requirements of the degree. Students should not be seen, or see themselves, as visitors to community settings, but as full participants in the life of the community.

- $\quad$ The students must be fully exposed to the social and cultural environment and thus come to understand the important elements of community life and the relationship of these elements to health related factors and activities (Carroll, Carter \& Hayes 1993: 168).

- The program must be of clear benefit to both the student and the community. This implies that the community must be actively involved in the educational program (WHO, 1987:31).

\section{Health promotion and illness prevention:}

In November 1986, the first international conference on health promotion was held in Ottawa, Canada (http:// www.hc-sc.ca/hppb/docs/charter). It built on the progress made through the Declaration on Primary Health Care at Alma Ata, and endeavored to create a similar international consensus on health promotion.

In the declaration at the end of the conference, health promotion was defined as follows: "Health promotion is the process of enabling people to increase control over, and to improve, their health. To reach a state of complete physical, mental and social well-being, the individual or group must be able to identify and to realize aspirations, to satisfy needs, and to change or cope with the environment. Health is therefore seen as a resource for everyday life, not the objective of living.

Health is a positive concept emphasizing social and personal resources, as well as physical capacities. Therefore, health promotion is not just the responsibility of the health sector, but goes beyond healthy life-styles to well-being." (http://www.hc-sc.ca/hppb/docs/charter).

Health promotion actions are classified as follows:

1. Building healthy public policy: Health promotion policy includes diverse but complementary approaches including legislation, fiscal measures, taxation and organizational change. This action requires the identification of obstacles to the adoption of healthy public policies in the non-health sectors, and work to remove them.

2. Creating supportive environments: The inextricable links between people and their environment constitute the basis for a socio-ecological approach to health. Changing patterns of life, work and leisure have a significant impact on health. The way society organizes work and supports leisure should help create a healthy society. This action requires the systematic assessment of the impact on health of these spheres of life, the built environment, the natural environment and the social environment.

3. Strengthening community action: Health promotion works through concrete and effective community action in setting priorities, making decisions, planning and implementing decisions to achieve better health. At the heart of this action is community development and empowerment.

4. Developing personal skills: Health promotion supports personal and social development through providing information, education for health and enhancing life skills. By doing so, it increases the options available to people to exercise more control over their own health and to make choices conducive to health. Enabling people to learn throughout life, to prepare themselves for all of its stages and to cope with chronic illness and injuries is essential.

5. Reorienting health services: The health sector must move increasingly in a health promotion direction, beyond its responsibility for providing clinical and curative services. Health services need to embrace an expanded mandate that supports the needs of individuals and communities for a healthier lifestyle, and opens channels between the health sector and broader social, political. economic and physical environmental components (http://www.hc-sc.ca/ hppb/docs/charter).

While health promotion deals with a population focus, illness prevention often deals with individuals, families and high risk groups. Illness prevention takes place when people at risk are identified, and measures are taken to prevent a specific illness or group of illnesses. It may take the form of policies, especially around protective clothing and practices (e.g. universal precautions), education of individuals or groups (e.g. informing pregnant women about the risk associated with smoking during pregnancy), and public health programmes, such as immunization or advocating the use of mosquito nets (Naidoo \& Wills, 1994: 19).

\section{Purpose}

The aim of this research was to describe and evaluate the outcomes of PBL/ COL programmes in nursing schools in South Africa in terms of community health nursing competence and continued self-directed learning and to compare the outcomes with those of graduates from conventional programmes.

\section{The research objectives were to:}

1. describe the incorporation of illness prevention, health promotion and an understanding of the context in nursing care of graduates from PBL and COL programmes and those from conventional schools of nursing in South Africa, as described by the graduates and their supervisors.

2. describe whether and how graduates from PBL/COL and conventional programmes were engaging them- 
selves in continued, self-directed learning.

\section{Definition of terms}

PROBLEM-BASED LEARNING PROGRAMME: This is a process-focused type curriculum in which students work in small groups on integrated clinical problems presented in the form of trigger materials on a sequence of patients. Students identify their own learning needs and address these, mainly through self-study, in order to solve the presenting problems (Barrows, 1986).

COMMUNITY HEALTH NURSING PROGRAMME. In this study this will refer to the competence of graduates to incorporate the prevention of illness and promotion of health into their practice, and to see health and illness in the wider context.

COMMUNITY ORIENTED LEARNING: COL for health professionals refers to education which is focused on population groups (aggregates) or individuals in the community, and which takes into account the health needs of the community concerned (WHO in Hamad, 1991:16). If more than $50 \%$ of the total clinical learning experiences are community-based, the curriculum is classified as community based. If there is a significant focus on community-based experiences, but the $50 \%$ level is not quite reached, it is a community-oriented curriculum (Barrows, 1986: 482).

CONTINUED SELF-DIRECTED LEARNING: In this study self-directed learning will refer to graduates accessing learning resources (human, programmatic or material) to address their continued learning needs which they have identified themselves.

CONVENTIONAL INSTRUCTION: This refers to contentbased curricula characterized by large group teaching mainly through lecture and demonstration methods, and limited self-directed learning.

\section{Research methodology}

This was a qualitative evaluation study, descriptive and comparative in nature. In-depth interviews with graduates and their supervisors were done and data analyzed using a template based on the theoretical framework set out above. Five aspects were dealt with during the interviews, two of which (stages of practice and problem-solving ability) have already been reported elsewhere. This article deals only with the aspects of community health, self-directed learning and general comments on PBL/COL programmes.

The population was the graduates of the four PBL schools and three conventional schools in the year under consideration. All graduates who could be traced and were in the country were approached by mail to take part in the study, and everybody who responded positively was included in the sample. The same was done for three traditional university nursing schools working in the same provinces. Each graduate was asked to identify a supervisor who had worked most closely with her/him. Both the graduate and the supervisor were interviewed once to obtain a description of the practice of the graduate. The non-PBL/COL group came from three universities comparable to the PBL/COL schools in terms of catchment area of students, race of students and language of teaching.

Although authors usually recommend that outcome studies involve graduates 12 months after completion of a programme (Clark, Goodwin, Mariani, Marshall and Moore, 1983: 55; Stufflebeam, 1987: ) the researchers decided to use 6 to 9 months after graduation instead. This decision was based on the fact that the services in which graduates may work are so diverse, that after a longer period of time it would be difficult to discount the influence of the setting, and hence ascribe differences only to the programmes. Furthermore, many graduates leave the country after one year for overseas experience, and this might make it difficult to access a representative sample.

All graduates from the graduating class of each participating nursing school were approached by mail and invited to participate. If they consented by returning the signed agreement, the nurse manager at their workplace was contacted for permission to interview the graduate and her supervisor. This was also done by mail, with a short proposal attached. If the nurse manager gave approval, the date and time for the interviews were set by the researchers.

The researchers each interviewed one group of graduates. The interviews were scheduled for times suitable to both, and were taped, transcribed and analyzed. In order to increase the validity of the data, staff from different universities interviewed each other's students, so that graduates were not inhibited by having to talk to their own lecturers. The interviews made use of open-ended questions and the ones relevant to the aspects discussed in this article were: 1. How do(es) you/she/he integrate prevention and promotion into your practice? Can you give a recent illustration?

2. When last did something in the clinical area puzzle you so much that you went to read up about it? Tell me about it.

3. Is there anything else you want to tell me?

Each researcher analyzed the data of one group of students. The Template Analysis Style described by Crabtree and Miller (1994) was used to analyze the data. This means that the concepts of interest to the researchers as outlined in the research objectives were used as a preliminary template, but the researchers had the freedom to revise categories before interpretation. Categories with regard to each concept were created as the analysis proceeded, e.g. types of health promotion and resources used for self-directed learning. The interpretative approach of Benner (1984) was used, so that data was not broken down into small pieces, and the rich description of actual practice was not lost. Data analysis was done using the NVIVO computer programme. To increase the validity of the coding, researchers worked with the same code book, checked each other's coding and finalized the comparisons together. No graduates willing to participate were excluded, even though data saturation was achieved.

\section{Ethical considerations}

Permission to undertake the research was obtained from 
Table 1: Work setting of graduates

\begin{tabular}{|l|l|l|l|l|l|}
\hline UNIVERSTY & \multicolumn{4}{|c|}{ WORKSETTING } & TOTAL \\
\hline & MIDWIFERY & GENERALUNITS & SPECIALIST UNITS & OTHER & \\
\hline FS & 2 & 4 & 9 & 1 (Clinic) & 16 \\
\hline NATAL & 2 & 4 & 4 & 0 & 10 \\
\hline WITS & - & 1 & - & $\begin{array}{l}2+ \\
2 \text { (Psych) }\end{array}$ & 5 \\
\hline UNITRA & 4 & 3 & - & $\begin{array}{l}1 \text { (OPD) } \\
1 \text { (Theatre) }\end{array}$ & 9 \\
\hline CONTROL & 1 & - & 7 & 1 (Psych) & 5 \\
\hline TOTAL & $9(18 \%)$ & $12(24 \%)$ & $18(41 \%)$ & 8 (16\%) & 49 \\
\hline
\end{tabular}

the Ethics Committees of each of the four universities utilising the PBL/COL approach in their curricula. Once the graduates had been contacted and they had agreed to participate in the research, written permission to interview them and their supervisors was obtained from the health authority at which they were working. At the time of interview, respondents gave verbal consent to be interviewed and they were reminded of their rights to withdraw from the study at any time and that should they not wish to answer any question they were free to refuse to do so. The interviews were conducted in a private setting with only the respondent and the interviewer being present any time.

\section{Sample description}

A total of 49 graduates were interviewed, of whom 40 were from PBL/COL programmes, and 9 from non-PBL/COL programmes. Of the PBL/COL group 25 were African, 2 Indian and 17 White, while 3 of the non-PBL/COL group were African and 2 White. In the PBL/COL group 1 was a male graduate, and in the non-PBL/COL group 2 were males.

In the year in which these groups graduated, the following numbers of students graduated from the different PBL/COL schools: Free State 73 (sample 16 or 22\%), Natal 24 (sample 10 or $42 \%$ ), WITS 9 (sample 5 or $56 \%$ ), and UNITRA 22 (sample 9 or $41 \%$ ). Since this was qualitative research, a specific sample size was not decided upon. The sample does seem to be reflect of the population of PBL graduates from these four schools.

The majority of the PBL/COL group were working in provincial services (27), while two of the non-PBL/COL group worked in this sector. Table 1 summarizes the areas in which the graduates were working. A total of 43 supervisors were interviewed. The highest proportion of graduates worked in specialist units $(41 \%)$, but general units and midwifery units were also well represented.

\section{Findings}

\section{Community Health Nursing}

There were many nurses and supervisors who described routines in answer to the questions related to health promotion and illness prevention instead of initiatives by the individual graduate. Most respondents found this a difficult question to answer, and much prompting was necessary before they even understood what was required. Only 13 examples of health promotion were described by respondents, while 75 examples of illness prevention were described. Of these 53 came from the graduates and 30 came from the supervisors. However, the categories were substantially the same. There does not seem to be a difference between the involvement in these activities of PBL/ COL graduates and non-PBL/COL graduates. (Refer Table 2).

\section{Health promotion}

Only three types of health promotion were mentioned by the respondents; increasing personal skills (5) mass education (4) and creating a supportive environment (4). One example of increasing personal skills involved a control group graduate teaching school children interpersonal skills with regard to the prevention of drug abuse.

Example: Mass education

I'm very passionate about preventive or promotive health. I run weekly programmes. I have chalkboards outside the Spar. I don't know if you saw it. The big electronic board. We go according to the weeks of the months where we do promotions. I will do free blood pressure, free cholesterol, I will do free glucose.... We advertise it there and people come in and we test them and do screening tests and from there we offer nutrition advice, offer advice on healthy eating, exercise, whatever is relevant, of course. So we are very much involved in healthy eating, lifestyle, stress management. We use those weeks to advertise on our boards to promote healthy lifestyles - to get people in. (Graduate) 
Table 2: IIIness prevention strategies used by graduates.

\begin{tabular}{|c|c|c|c|c|c|c|c|}
\hline Strategy & Respondent & FS & Natal & WTTS & UNTRA & Control & Total \\
\hline \multirow[t]{2}{*}{ Health education } & Grad & 9 & 8 & 4 & 4 & 5 & \multirow{2}{*}{$\begin{array}{l}46 \\
(55 \%)\end{array}$} \\
\hline & Super & 5 & 1 & 1 & 7 & 2 & \\
\hline \multirow[t]{2}{*}{ High risk identification } & Grad & 1 & - & - & 1 & 2 & \multirow{2}{*}{$\begin{array}{l}9 \\
(11 \%)\end{array}$} \\
\hline & Super & 1 & - & - & 3 & 1 & \\
\hline \multirow[t]{2}{*}{ Med-surgical asepsis } & Grad & 4 & 2 & 3 & - & 5 & \multirow{2}{*}{$\begin{array}{l}21 \\
(25 \%)\end{array}$} \\
\hline & Super & 4 & 1 & - & 2 & - & \\
\hline \multirow[t]{2}{*}{ Preventing complications } & Grad & - & 2 & 2 & - & - & \multirow{2}{*}{$\begin{array}{l}6 \\
(7 \%)\end{array}$} \\
\hline & Super & - & 1 & 1 & - & - & \\
\hline \multirow[t]{2}{*}{ Immunization } & Grad & 1 & - & - & - & - & \multirow{2}{*}{$\begin{array}{l}2 \\
(2 \%)\end{array}$} \\
\hline & Super 1 & - & - & - & - & - & \\
\hline Total & & 26 & 15 & 11 & 17 & 15 & 84 \\
\hline
\end{tabular}

Example: Creating a supportive environment

"She was also maintaining a hazard free environment so she was maintaining safety of the patient by seeing to it that the sharps are put in the correct container and also our equipment because sometimes we do have those long stands that might fall and hurt the patient. She made sure that they were kept safe." (Supervisor)

\section{IIIness prevention}

The two most common activities mentioned by both the graduates and the supervisors, in this area of practice were health education (55\%) and medical-surgical asepsis (25\%).

The health education practices mentioned pertained mainly to the following :

- pregnant women coming for antenatal care,

- patients with chronic conditions such as diabetes,

- $\quad$ pre-discharge education of patients to prepare them for self-care at home,

- child care, e.g. infant feeding, care of umbilical cord,

- family planning.

A UNITRA graduate reported that they observed that pregnant women used a traditional medicine called "isihlambezo" that resulted in precipitate labour. They felt that education was essential for pregnant women in order to reduce complications, one of which they observed as foetal distress.

So in order for the relapsing, you have got to get the family involved. So it's a lot of support and reassurance and giving out pamphlets. Putting them in touch with support groups and with the patients themselves, as well you have to teach the signs and symptoms because we all know when we start getting sick,... When we educate the family we educate the community because they are going to go back and tell their friends what they have learnt about schizophrenia or bipolar or whatever... (Graduate)

The examples of vigilance in nursing care to prevent complications also show a keen awareness of the preventative role of the nurse.

"And even during bath I ask people.. we must, even if it is a slight thing that we think is not going to help telling the sister about, you must try and report each and everything that you see on the patient Even if the thing is stupid. Maybe it won't be stupid when you (inaudible) and it might help the patient's health."

Interviewer: "Give me an example of the small things that you think should be reported."

Graduate: "Even the bruises, people take it lightly that there is a bruise on the patient say the bottom. Maybe it was caused by a creased sheet, maybe it's because you are not doing turnings and in accordance to the right procedure."(Graduate).

\section{Contextual understanding}

The responses from supervisors and graduates were perused for comments indicating that the wider context of the patient was taken into account during nursing care. In PBL/ COL programmes, one would hope to see graduates have a wider view on health and illness. A few graduates made comments that indicated that they took the context of the patient into consideration during patient care. Such exam- 
ples included graduates referring to age, family situation, health habits and community characteristics.

"From the post-operative point of view when they are going home, I find that I do spend a lot on patient education and looking through the community resources that they have in their own local communities to go home to, what signs and symptoms' they can look for, say for suture infection. And that basically is my promotion and prevention." (Graduate).

\section{Discussion}

Respondents could identify many more incidents relating to illness prevention than of health promotion. This might be related to the fact that very few of the respondents worked in a Primary Health care setting, where such interventions can be expected to be more common. The environments therefore were not conducive to a strong focus on health promotion. However, according to the Ottawa Declaration on health promotion (http://www.hc-sc.gc.ca/ $\mathrm{hppb} / \mathrm{phdd} / \mathrm{docs} / \mathrm{charter}$ ), the reorientation of secondary health services is one of the major strategies of health promotion. The fact that the graduates were mainly working in hospitals should therefore not have prevented activity in relation to health promotion.

The greater number of responses to activities related to illness prevention as compared with health promotion may also be related to the fact that respondents had difficulty in comprehending and distinguishing between the two concepts. It is true that most supervisors trained before community health nursing was incorporated into pre-registration training, but graduates also had difficulty with the concept of health promotion. This might be related to the continued emphasis on individual illness care and illness prevention in many primary health care clinics, as opposed to truly aggregate-focused, community-based health promotion. Carlisle, Luker, Davies, Stilwell \& Wilson (1999: 1256) point out that in the UK Project 2000 was aimed at preparing nurses to deliver care in the new health environment of the new millennium. They then argued that their findings "begs the question as to whether these nurses are being prepared for an environment that does not exist in some organizations" (1999:1262). The same question can also be asked about preparing nurses from a philosophy of primary health care, for a service, which in many settings does not function in the primary health care mode.

As far as Illness Prevention is concerned, most examples focused on health education, medical and surgical asepsis, and prevention of complications through vigilance. This aspect of nursing practice probably needs further exploration. It might very well be that the deficiencies found by Latter et al (2000: 1286) in the UK, are also applicable to the graduates from SA degree programmes, notwithstanding the PBL/COL approach.

The fact that so few graduates were working in PHC settings needs some comment. All four PBL programmes are also COL programmes, but only two out of the total of 40 graduates from these PBL-COL programmes worked in PHC settings 8 months after graduation. One graduate said that she had tried to get a post in a clinic, but was told that there is a policy that graduates have to work 2 years in a hospital setting before they can work in a clinic. How general such policies are that put a barrier in the way of nurses who want to be community health workers, is not known.

\section{Continued Self-directed Learning}

In this section the PBL/COL group distinguished themselves by showing a questioning attitude. Both supervisors and graduates commented on this attribute as characteristic of these nurses. The non-PBL/COL group also continued learning, but there was not the same strong emphasis from these respondents on their general attitude to learning.

\section{Resources for continued learning}

The most common resource was their own textbooks. The example below is typical of a graduate identifying an own learning need, and taking steps to address it.

"To be honest I was not aware of how to diagnose face to pubis presentation. So I saw the need to go and visit the library." (Graduate).

The graduates also made use of other people such as doctors and senior staff members as resource persons.

"If the doctor does something, you are not afraid to ask 'why?' If you do not understand you say 'Please sit down and tell me exactly'. We are able to ask and are not afraid. We want to learn more about anything." (Graduate).

Some graduates also use the library, books made available in the units, the internet, continuing education in the work setting, and one had even done a short course in the time since graduation.

\section{Attitude towards continued learning}

The positive attitude of graduates toward continued learning is reflected in the following two examples:

"When I did my month in the nursery (as a student) that was all we really didn't spend long in the nursery. Our training hospital didn't really have a nursery we just did post natal care together. So in the nursery (where she worked after graduation) I was looking up a lot of medications for babies, side effects you know, Medications change all the time. We use different drugs completely and that kind of thing I read up all the time. I think every day I go home and read something up. Learning all the time." (Graduate).

There is a library here so I take out some new research books. They help you to learn new things. Even the doctors help during rounds if you tell them that "we are new - just qualified" (Graduate).

One graduate, however reported that they feel isolated because "During our training we were exposed to many things such as workshops, symposia. In-service education is scarce. I think this is going to demoralise others". (Graduate). 


\section{Discussion}

At this stage of their professional careers it would seem that the vast majority of graduates continue learning. They identify their own learning needs, and address these by using the resources at hand. Only graduates from the PBL group refer to learning to "keep up to date" and not just learning to address a gap in their knowledge or understanding.

In this regard it would seem that the environment in many settings is not conducive to supporting the learning of graduates over the longer time. Most of them refer to their own textbooks. These would become obsolete within a few years, and are not good resources for current evidencebased practice. Already some of the graduates pointed out that libraries and other learning resources are totally absent where they work. It is all very well for educational institutions to encourage life-long learning for the health services, but it is incumbent on the health services to provide an environment which nurtures this ability and attitude.

In the view of most graduates and their supervisors, the advantages of PBL programmes far outweigh their weaknesses. Most of the advantages mentioned refer to the personal development of the students. It would therefore seem that these programmes succeed in producing a person who does not only know and can do, but a person who believes in her/himself, can work with other people, and can work in the system.

\section{Additional Findings}

\section{The Quality of supervisors' contributions}

The descriptions by the supervisors were often very thin, either in terms of content, or in terms of the attitude or insight they showed. Supervisors often seemed to have little knowledge of the practice of the new graduate under their supervision. Since they were all identified by the graduates as "the supervisor working most closely with you", that means that in reality very little real supervision takes place. Secondly, many supervisors seemed to have a very limited understanding of concepts such as problem-solving and its place in nursing practice, prevention and promotion and continued learning. Even when given a number of prompts, and time to think about it, they often could not think of anything in the practice situation exemplifying these concepts.

One can speculate that this might be a result of their not being used to using these concepts. Supervisors might also have less opportunity to talk about their perceptions of nursing and nurses, and therefore be less ready to verbalize on these subjects than recent graduates. Whatever the reason, the poor verbal ability of these experienced nurses has to have an influence on their interaction with other team members, thus limiting their influence and effectiveness. This is surely something that needs to be addressed in continuing education for mid-level managers.

In their literature survey of role modeling in professional socialization, Fitzpatrick, While and Roberts (1996: 512) found that role models are important at all stages of professional life. The quality of the inputs from the supervisors interviewed, raises the question of where young entrants to the profession will find their role models.

Another perennial problem is the negative attitudes supervisors generally expressed about degree programmes. They very often pointed out that "this graduate is different, of course", but did not allow this to interfere with their basic belief that degrees did not prepare good nurses. Some of them admitted that they had little or no experience of working with such graduates, but this also did not deter them from being convinced that they are bad. Graduates referred to this attitude also prevailing in their training hospitals, and one wonders what this lack of acceptance by colleagues does to shape the graduates. The general attitude is reflected in the two quotations below.

"I would like to say that I really impressed with her. You know, often I know I trained at (hospital A) and I was a charge sister at (hospital A) for many years and then a matron and I think that a lot of the diploma girls feel that the varsity girls aren't that good, that they don't have the practical experience and all of that. I must admit I have never had that experience with the varsity girls. As I say her partner $M$ is an excellent midwife as well and I must admit when I was going to get a newly qualified university student I was a bit worried about her practical hands on experience because they don't spend as many practical hours in midwifery as the diploma girls but I also did the integrated course and I didn't either and I don't think I'm a bad midwife and as I say she's really outshone herself I said it it's not often that I get the doctors telling me about a new staff member it takes them a long time but you know with little comments" (made by the doctors that she is good). (Supervisor)

"It's a learning experience for everyone and each year if we encountered problems we would go to the staff about it and they would try and help us out about it. But I think if I had to compare myself with the diploma girls I've got two new sisters working with me who qualified the same time as me with diplomas and they would say there's no difference. I'm not less qualified or less experienced at all. I' $m$ as competent as they are. But then again they had the same midwifery experience. But even you know I wasn't very good at putting up drips I hadn't had much experience, they were the same. If find that we all battled. You know especially with night duty, you're left alone so you've got to learn how to do things and we all have the same fears. (Graduate).

\section{Problems in relationship to medical colleagues}

Many of the incidents recounted by respondents had to do with conflict between nurse and doctor. It often involved doctors not responding to or taking seriously the observations or reports of nurses. Many of these incidents had negative results for patients, unless the nurse was assertive enough to ensure that her/his input be respected. There 
were also incidents of doctors not taking responsibility for their own mistakes, but blaming them on the nurses.

\section{Discussion}

\section{Comments about PBL programmes}

PBL/COL graduates made many comments in which they articulated the strengths of their programmes (see example below). They knew exactly how their learning worked, what made the difference between before and after their training, and between them and other nurses. Only a single non$\mathrm{PBL} / \mathrm{COL}$ group nurse spontaneously referred to a specific positive attribute of her training programme. It is not so much that they mentioned negatives, but that they were silent about their learning programmes. This is not true of the PBL/COL group, who were articulate about their programmes.

"It's a wonderful experience that I think everybody should go through. I mean it's an excellent working or study technique or whatever you want to call it andwe grew through it. Over the four years we hated it. She's (the facilitator) sitting there and we are supposed to do all the work, that's how we actually perceived it, you know. She's sitting there and you have to go to the library, oooh, it was hectic. But once you got the hang of it, it was actually fun. You were controlling your own studies. ...It was fun being in control of the class, instead of the lecturer." (Graduate).

Two deficits of PBL/COL programmes were mentioned across sites, but only by very few graduates. The deficits were limited content or time to study the content, and limited clinical learning, either through the time being too limited, or through clinical teaching being inadequate. When supervisors mentioned deficits, it was always a generalization, and not referring to the specific graduate. For instance one said: "when you have been given them to supervise you have got to teach". (Supervisor).

PBL/COL graduates were in the main very positive about their programmes. They mentioned a number of strengths across sites. The first strength contradicts the graduates who saw clinical experience as a problem, since many graduates and supervisors remarked that they were good practically. Here are examples of the general comments made by graduates from the $\mathrm{PBL} / \mathrm{COL}$ groups:

- $\quad$ PBL/COL enabled them to work independently and are critical thinkers "because I learned to be selfdirected and not necessarily depend on someone". (Graduate)

- $\quad$ PBL/COL taught them how to learn from others in the clinical situation "Most of the time in PBL we stayed close to the ward nurses because we knew that we needed to work closely with them in order to learn. That has helped me to learn to work with others." (Graduate).

- PBL/COL gave them self-confidence: "In the beginning of each year we would look at our syllabus and think there is no way I can do that. Each assignment you come to you say this but at the end of it, the end of the year, you look back and you actually realize you can do it." (Graduate).

- $\quad$ PBL/COL made them flexible and adaptable: "I think I've adapted quite quickly, I know' a lot of girls who didn't have the same background as I did and didn't have the same courses and a lot of them have battled and a lot of people come and go out of the labour ward. But I think I've been okay. I feel it's because I' $m$ able to solve problems and work them out myself.'(Graduate).

- $\quad$ PBL/COL taught them to cope: "In the beginning, while I was a student, I hated PBL because I just thought I would never get through all the stuff I needed to get through and stuff like that. I needed a basis, a foundation that I could build on that.

But now that I' $m$ working I realized that PBL has taught me how to assess situations, how to cope with situations and it is a good thing really. In the beginning I really didn't want it. My attitude was I'm teaching myself and I'm paying so much and now I look at it I think you know what they were there to guide us." (Graduate).

A number of supervisors also found the graduates very caring and empathetic with patients. This is heartening in the light of the Batho Pele campaign and the continuing debate around uncaring nurses.

"I have noticed too she is very, how should I put it, empathic. I know therewas one patient that lost a relative. She took her time actually being with them.

Not crying but trying to talk to them, helping them to contact some other relative and she really took her time. Listening to what they were saying and trying very hard to help them until their problem was solved. They were able to contact the people they wanted to contact and again helping them to collect their belongings. She is really very helpful in that aspect" (Supervisor).

One of the strongest qualitative differences between the $\mathrm{PBL} / \mathrm{COL}$ and non-PBL/COL groups was in the personal development that the $\mathrm{PBL} / \mathrm{COl}$ group displayed to others, to interviewers and to their supervisors. One interviewer summarized this as follows: "The PBL/COL group was blossoming, but the others were just ordinary". Many of the examples already quoted in this report illustrate this difference. A few more are quoted below.

M's very confident. Very, very confident. Taking rounds with doctors, with the superintendent. And well, she speaks freely to the superintendent. She's got confidence. She's been very good, actually she left (our hospital) now it's a loss to us. (Supervisor)

She is very conscientious, very hard working. She will always contribute and take part. Not only the patients in the ward, but for instance we had a fun walk and we are going to have a fete or a fair at the end of October, and she wanted to help and do things. She painted this for us. (She said) 'I think we must do this for the parents.' (and) 
'Can't we do this for the ward?' She is very involved for the short while she is here. From January she has done more for the ward than some of the staff members that have been here for five years. (Graduate).

\section{Conclusion}

Based on the findings in this research, the following recommendations are made with regard to further research:

1. The development of graduates over time, and the influence of the role models and supervision they receive in the workplace, should be further explored.

The following recommendations are made for nursing education:

2. The health promotion strategy "reorientation of the health system to health promotion" should be given more attention in educational programmes.

3. Multidisciplinary teaching should be promoted to enhance working relationships between nurses and colleagues in other health professions.

The following recommendations are addressed to the health services:

4. Nurse managers should scrutinize policies to identify and change those which limit professional development and functioning, and limit movement of new graduates into $\mathrm{PHC}$.

5. Continuing education of mid-level managers should include enhancing their ability to think and talk in a professional manner about scientific subjects.

The following recommendations are addressed to the organized profession:

6. They should also take up the issue of doctor-nurse conflict in a constructive manner with the organized medical profession.

\section{References}

ALBANESE, MA \& MTCHELL, S 1993: Problem-based Learning: a review of literature on its outcomes and implementation issues. Academic Medicine 68(1): 52-81.

BARROWS, HS 1986: A taxonomy of problem-based learning methods. Medical Education 20: 481-486.

BENNER, P 1984: From novice to expert. Menlo Park: Addison-Wesley Publ. Co.

BLECHER, M \& FRANKISH, JG 1995: District based health services. S.A. Family Practice. April.

CARLISLE, C; LUKER, KA; DAVIES, C; STILWEI L.J \& WILSON, R 1999: Skills competency in nurse education: nurse managers' perceptions of diploma level preparation. Journal of Advanced Nursing 29(5): 1256-1264.

CARROLL, MC; CARTER, SV \& HAYES, ER 1993: Attributional theory applied to a Baccalaureate Nursing Community experience. Journal of Nursing Education (32)
4. $163-169$.

CLARK, T; GOODWIN, M; MARIANI, M; MARSHALL, M \& MOORE, S 1983: Curriculum evaluation: an application of Stufflebeam's model in a Baccalaureate School of Nursing. Journal of Nursing Education 22: 54-58.

CRABTREE, BF \& MILLER, W L 1994: Doing qualitative research. Newbury Park, Sage Publications.

ESHLEMAN, J \& DAVIDHIZAR, R 1997: Community Based Nursing Education: A five stage process. International Nursing Review 44(1):24- 28.

FITZPATRICK, JM; WHILE, AE \& ROBERTS, JD 1996: Key influences on the professional socialization and practice of students undertaking different pre-registration nurse education programmes in the United Kingdom. International Journal of Nursing Studies 33(5): 506-518.

HAMAD, B 1991: Community-oriented medical education: what is it? Medical Education 25: 16-22.

INTERNATIONAI.CONFERENCEONHEALTHPROMO TION 1986: The Ottawa Charter on Health Promotion. http://www.hc-sc.gc.ca/hppb/phdd/docs/charter

LATTER, S; RYCROFT-MALONE, J; YERRELL,P \& SHAW, D 2000: Evaluating educational preparation for a health education role in practice: the case of medication education.. Journal of Advanced Nursing 32(5): 1282-1290.

LITTLE, P \& RYAN, G 1988: Educational Change through Problem-Based Learning. Australian Journal of Advanced Nursning. 5 (4) : 31-35.

NAIDOO, J \& WILLS, S 1994 : Health Promotion. London : Balliere Tindall

RICHARDS, R \& PHLOP, T 1987: Innovative schools for health personnel. Report on ten schools belonging to the Network of Community Oriented Educational Institutions for Health Sciences. Geneva: WHO, 1987.

STUFFLEBEAM, DL 1987: The CIPP model for programme evaluation, in Madaus, G F, Schriven, $M$ and Stufflebeam, D L (eds) Evaluation models: viewpoints on educational and human service evaluation. Boston: Kluver-Nijhoff.

VERNON, DTA \& BLAKE, RL 1993: Does Problem-based learning work? A meta-analysis of evaluative research. Academic Medicine 68(7): 550-557.

WORLD HEALTH ORGANIZATION 1987: Communitvbased education of health personnel. Technical Report Series No. 746, Geneva: WHO.

UNIVERSITY OF NALAL FACULTY OF MEDICINE 1991: Community based medical education. First Annual Report. Durban: University of Natal. 


\section{Acknowledgements}

The financial assistance of the National Research Foundation towards this research is hereby acknowledged. Opinions expressed in this report, and conclusions arrived at, are those of the authors and are not necessarily to be attributed to the National Research Foundation. 